\title{
Placement of fin type dental implant in three different surgical situations of alveolar bone
}

\author{
Coen Pramono D \\ Department of Oral and Maxillofacial Surgery \\ Faculty of Dentistry, Airlangga University/Dr. Soetomo, General Public Hospital
}

Surabaya - Indonesia

\begin{abstract}
Three different dental implant placements according to surgical implant bed situations were observed in its bone integration 3 months after dental implant insertion. This observation was done on implant system which has plateau or fin system. Elf implants were placed in the upper jaw in two patients. In case one, two implants were inserted immediately after tooth extraction, and the other six implants were placed in the alveolar crest regions in delayed implantation or in which the teeth had been extracted over 6 months of period. In case two, three implants were inserted in the post trauma region in the anterior maxilla, which the labial plate had been lost and reconstructed with bone grafting procedure using a mixture of alloplastic and autogenous bones. The alveolar reconstruction was needed to be performed due to only thin alveolar crest width was left intact. All of those implants observed showed in good integration.
\end{abstract}

Key words: Fin implant system, Immediately dental implant placement, Alveolar crest width reconstruction, Mixture of autogenous and allogenic bones

Correspondence: Coen Pramono D, c/o: Bagian Bedah Mulut, Fakultas Kedokteran Gigi Universitas Airlangga. Jln. Mayjend. Prof. Dr. Moestopo 47 Surabaya 60132, Indonesia.

\section{INTRODUCTION}

A modern technique in oral rehabilitation using dental implant brought dentistry into a new chance in giving a good service to the patients who need for dental rehabilitation after missing their teeth. The use of dental implant may lead a comfortable result and may preserve the neighboring teeth while the dental implant needed only a single retainer i.e. bone, differs when the tooth rehabilitation is done using fixed denture using a bridge technique which at least two teeth are necessary to be half cut in creating new attachment for the lost tooth.

Many implant systems have been produced with its advantages and disadvantages. Implant system using fin or plateau form surface colored the dental implant world with its unique system which has a different system as usually found in other implant system, while this system is applied not in screw type but by inserting the implant into precise prepared bone holes exactly according to the implant diameter needed to be inserted.

The unique implant systems using fin type found in its implant body, which has a fin design and offers at least $30 \%$ more surface area than a screw implant type of the same size and affords direct resistance to vertical forces of occlusion on the surrounding haversian bone. Additional implant retention is achieved through bone growth between each fin and integrated into implant surface as seen in the histologic level.

Retention of fin type implant is achieved through three mechanisms: first, precession placement of the dental implant body into the alveolar crest and the initial fitting is achieved, secondly bone growth between each fins this finding supported by the histological study showed that mature haversian bone surrounding the fins, ${ }^{1}$ and tertiary is integration between bone and implant surface. ${ }^{2-4}$

According to the advantage of this dental implant system as reported by some authors, ${ }^{5-13}$ this type of implant was selected for observation. The observation on immediate and delayed implant placement was done based on experiences in using screw-shaped type implant system which sometimes found with difficulty in its utility during the drilling process on thin and narrow alveolar crest as it with the risk of alveolar wall perforation. This problem might be happened when a high speed drilling is used.

As shown in the previous report, placement of screwshaped type implant using both immediate and delayed technique had been proved with a good result. ${ }^{14}$ Problem lead on the drilling speed during screw type implant placement which need about $800 \mathrm{rpm}$ for bone preparation therefore using this high speed rotation in thin alveolar width might give a risk to alveolar perforation. Different with what given in the utility of fin type implant that need only low speed drilling of $50 \mathrm{rpm}$ or less and in such cases when slowest drilling rotation is needed a hand drilling instrument also available to prevent alveolar bone from perforation or rupture. Therefore dental implant with fin system was chosen as an implant system used for observation. 


\section{CASES}

Case 1: A 56-year-old man asked for teeth replacement with dental implant. He was complaining of uncomfortable removable partial denture and felt badly disturbed as the partial denture influenced his phonetic quality, unpleasant by eating and feeling of boring in the maintainance of the denture. The lower jaw partial denture was than thrown away, because of the vomiting senses every time he wore the denture. Twelve teeth were observed and needed to be replaced, and planned with dental implant placement for the dental rehabilitation, eight dental implants in the upper jaw and four implants in the lower jaw. The teeth were $11,12,14,15,16,24$, 25, 26, 34, 36, 44, 46 (Figure 1). The upper jaw was the first priority to be restored as it is more related with aesthetic and those in the lower jaw were ceased temporarily waiting for the next setting.

The problems in this case were the alveolar crest in the regions of teeth 11 and 12 which were found atrophic in the labial site and atrophic maxilla in the region of tooth 26. Three point three millimeter $(3.3 \mathrm{~mm})$ of implant diameter
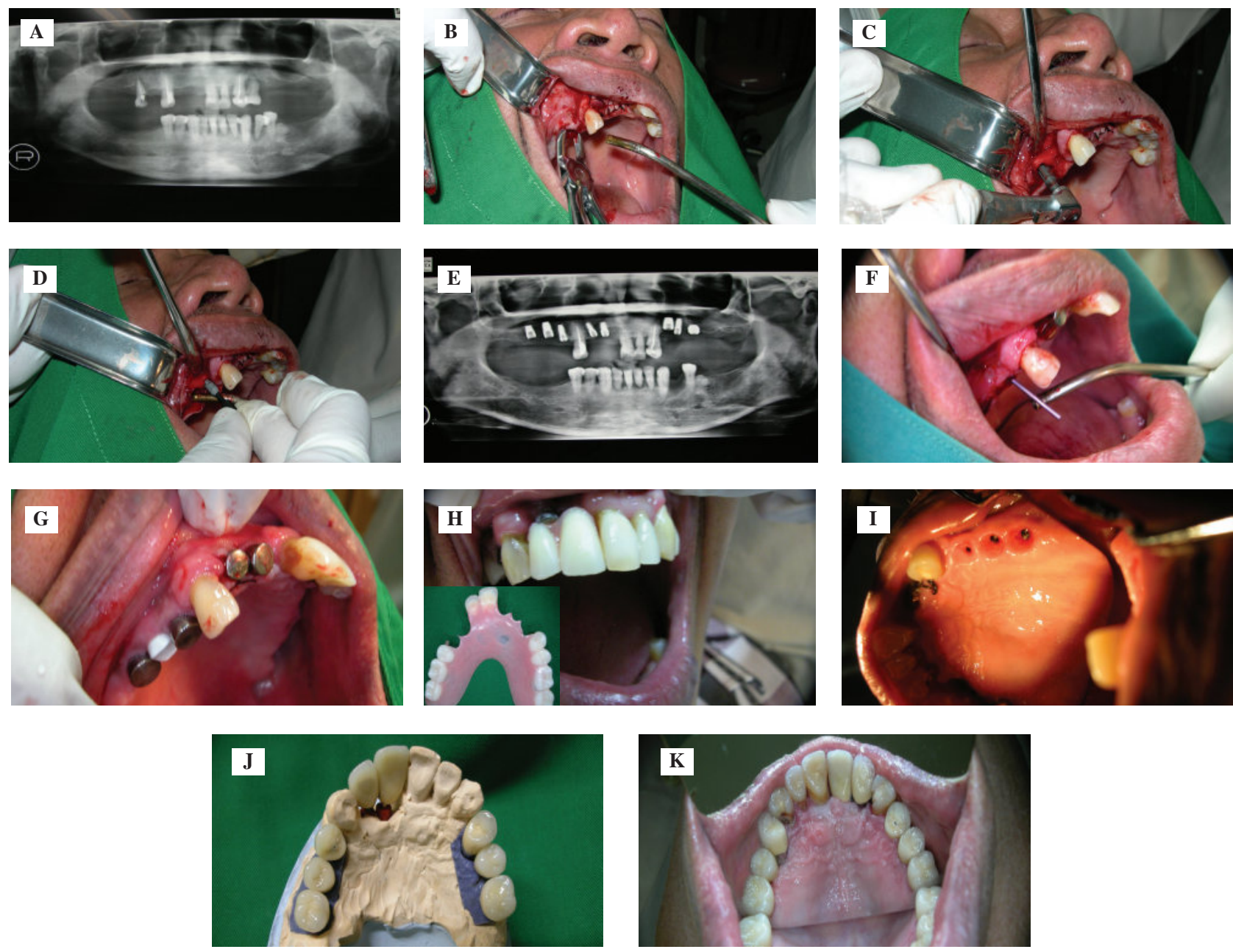

Figure 1. (A) Panoramic x-ray shows edentulous region in the upper and lower jaws. Twelve teeth implants were planned in the upper and lower jaws in teeth: $11,12,14,15,16,24,25,26,34,36,44,46$. In teeth 15 and 24 planned with immediate implant placement. Severe radiolucent areas shows around tooth 15 and 24; (B) Tooth extraction before implant placement; (C) Bone drilling and; (D) Five implants were inserted in the right upper jaw: 11, 12, 14, 15, and 16. Immediate implant placement after extraction of teeth 15 and 24; (E) Panoramic x-ray four months after placement of eight implants in the region of teeth: 11, 12, 16, 15, 17, 24, 25, and 26. Immediately placement in teeth 15 and 24; (F) Osseointegration evaluation method: Guide pin inserted into each implants and mobilization test is done; $(\mathrm{G})$ Eight temporary abutments were placed for sulci forming; (H) Temporary removable denture was made for cosmetic reason seated above the temporary abutments; (I) Example of three sulci and implants wells successfully formed. Situation in five days after temporary abutment removal; (J) Eight integrated crown-abutment ready for insertion; (K) Mouth mirror reflection: eight integrated crown-abutment inserted in teeth $11,12,14,15,16,24,25$ and 26. 
was used in the anterior regions and in tooth 26 , a short implant of $5.7 \mathrm{~mm}$ long and $6 \mathrm{~mm}$ diameter were inserted to cope the problem with success. Interesting problems were found in teeth 15 and 24 where in these regions the teeth were surrounded with granulation tissues. Two implants were immediately inserted into fresh extraction sites of teeth 15 and 24 presented with well integrated as no were found mobile implants. The other six implants which had been placed in delayed placement and also presented with a good result. The sequence of those implants placement can be seen as shown in Figure 1B to K.

Case 2: A 19 year-old female asked for teeth replacement after having accident 3 months previously. In the post trauma region showed with width defect presented with a thin paper alveolar crest exhibited had lost its labial bone plate which thought to be impossible for an implant placement (Figure 2A). Alveolar reconstruction was done for rebuilding the alveolar width using a mixture of autogenous and allograft bones. The autogenous bones were taken from the chin and retromolar regions and prepared in a mixture with allogaft bone material liquefy with her own blood and harvested into the region of alveolar crest of teeth 21, 22 and 23 and covered with an allograft membrane using double layer technique (Figure 2B-E). One year after bone implantation the reconstructed alveolar crest formed and healed perfectly and three dental implants were inserted in this region.

One year after the alveolar crest reconstruction the alveolar width had increased positively and showed with matured bone (Figure 2F). Although it has a different quality in its density comparing to the original bone beside the grafted region but still presented as an acceptable bone for implant placement. This bone quality was qualify during the initial drilling and marked softer comparing to the healthy bone, therefore hand reamer was obligatory to be used to prevent the labial bone from fracture. Periapical xray taken one month after implant insertion presented bone had been grown between the implant fins showed with no bone gab between the surrounding bone and all implants sites (Figure 2G).

One month after implants insertion showed bone had been integrated between the implant fins as seen in Figure 1G. Definitive integrated crown-abutment will be inserted three months after the implants placement.

\section{CASES MANAGEMENT}

Two patients asked for dental restoration in their partial edentulous jaws. Both patients were wearing removable dentures and complaining of discomfort. Therefore they asked for another alternative restorative treatment and dental implant was offered for those teeth rehabilitation and Bicon implant system with hydroxyapatite (HA)-coated surface was used.

In case 1, two problems had been mentioned as the atrophic site in the region of upper left first molar therefore a short type implant dimension was needed. Replacement of teeth 15 and 24 were planned with immediate implant placement into fresh alveolar socket after the teeth being extracted. A short dimension with only 5,7 mm length and diameter of $6 \mathrm{~mm}$ was used. Therefore problems of short
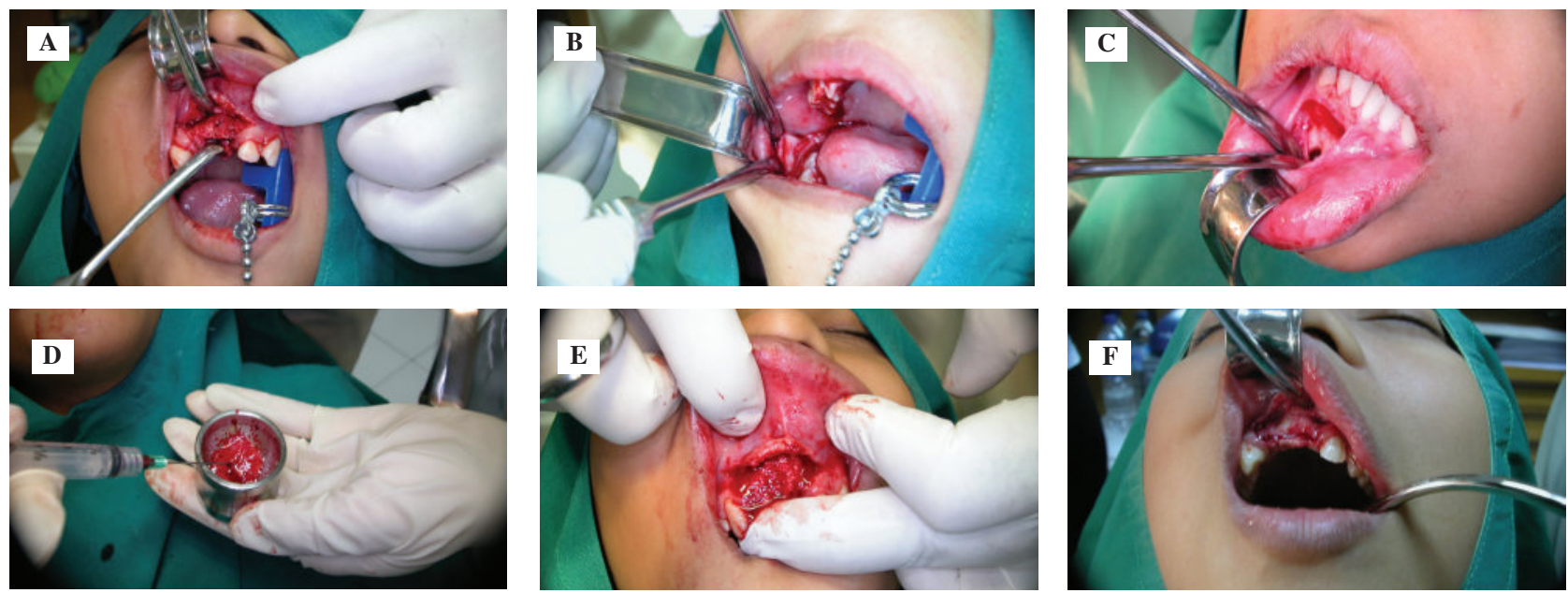

Figure 2. (A) Defect of the alveolar crest in the region of 11, 12 and 21 presented with no the labial bone and prepared for bone grafting; (B-C) Autogenous bone taken from the lateral retromolar and chin regions, bone puncher was used; (D) A mixture of autogenous-allograft bone materials and blood; (E) Harvested into the alveolar crest region of teeth 11, 12 and 21; (F) One year situation after alveolar crest width reconstruction; (G) Periapical x-ray one month after insertion of three dental implants for replacement of teeth 11,12 and 21 presented with no dental implant-bone gap.

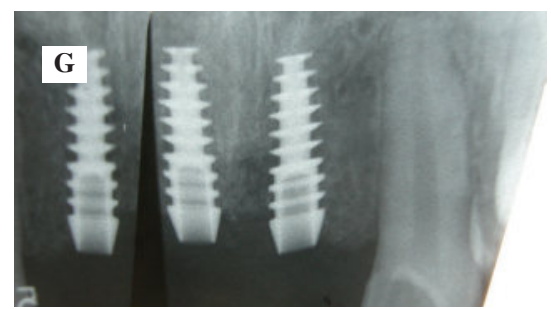


available bone in molar region of left upper jaw may be solved with this system.

In case 2, the necessary of alveolar crest reconstruction after alveolar crest trauma made this case included in this observation.

Coen's measurement technique was used to qualify the available bone height in all sites needed to be replaced with dental implant. ${ }^{15}$

\section{DISCUSSION}

Denture restoration using dental implant is now widely accepted through out the world. All of the dental implant system offered a success in its utilization and those had been reported by many authors that all of implants market can be well integrated with the surrounding bone as all implants usually designed with treated surface to ensure bone to be well integrated with the implant surface.

Easy and safety in its utilization during implant placement is the most important part in dental implant placement. One of important factor for success in implant placement is depend on a step during bone preparation procedure and it should be importantly considered as complication during bone preparation for example implant wall perforation will complicate the implant placement while it may lead of a failure.

There are three types of implant systems known, screwshaped, screw-hollow cylinder and hollow-cylinder. The screw-hollow and hollow-cylinder system had never been market in ours before, only the screw-shaped type implant is available. The implant system with fin or plateau surface seemed had been developed as a combination from hollowcylinder and screw-shaped implant systems. The fin or plateau system which developed by Bicon has a unique body design and available in three surface types. These three treated types surfaces are: TiO2-blasted, HA coated and titanium plasma sprayed coated (TPS). Those implant surfaces treatment has been made to allow a better contact between bone and implants. ${ }^{1-4}$

Three types of retentions can be expected in fin system, as 1) the precision bone hole according to the implant diameter, 2) the implant plateau or fins, affords direct resistance to vertical forces on surrounding haversion bone, and 3) the HA coated permitted a good osseointegration between implant and the surroundings bone. Studies on anchorage of implant surfaces to the surrounding bone had been studied by some authors.

Gotfredsen et al. ${ }^{2}$ in 26 rabbits with totally 156 implants placed in the tibia. Three types of implant surface had been observed, as TiO2-blasted surface, TiO2-blasted coated with hydroxyapatite and the control was machine type implant. The result showed that $\mathrm{TiO} 2$ blasting on implant surface improves the implant anchorage and in TiO2blasted surface coated with HA also presented improvement of bone contact but not yet practicable.
Histological and histomorphometric comparasion of bone to implant contact of immediately placed HA coated and TPS implants studied by Karabuda et al. ${ }^{3}$ showed that the HA coated surface can achieve better bone contact than given in TPS when placed into fresh extraction socket.

The investigation from Novous et al. ${ }^{4}$ also presented with the same result, where the HA coated implant may improved better bone contact comparing to machined and TPS sprayed implants but less superior comparing to soluble particle (SBM) surface implant.

This observation made base on experiences using screwshaped type implant placed both in immediate placement into fresh extraction socket or in delayed placement. ${ }^{11}$ Although in that previous report placement of immediate and delayed implant placement using screw type implant presented with a good result, ${ }^{11}$ but in such cases, the use of bone drill driven into a speed of $800 \mathrm{rpm}$ as usually used in the screw type dental implants placement might be risky comparing to the drilling speed needed for placement of dental implant used in the dental implant has a fin system.

Besides the alveolar height, preservation of the alveolar crest width during bone drilling should be considered important as perforation of the labial or palatal walls would lead a failure. As it might facilitate the fibrous tissues grown in between the dental implant and the alveolar bone wall sites and promoted of those surrounding implant socket walls absorption.

In cases of thin alveolar crest width, in the regions which had been received bone grafting or in the soft bone region, bone drilling using a low speed drilling with $50 \mathrm{rpm}$ or less or using hand reamer technique proved to be a safe procedure because alveolar wall perforation or even rupture can be easily ovoid and may also providing safely distal bone margin. Using hand reamer or a low-speed drilling with less than $50 \mathrm{rpm}$ might also provide bone debris that can be used for autogenous bone transplant material which usually necessary to be harvested immediately in the region around the dental implant neck after fin implant type insertion.

Retention of the dental implant into the surrounding bone bed plays as an important role to achieve success in all types of dental implant placement. In this fin type mplant, initial fitting can be easily provided therefore bone integration into implant surface can be expected. Achieving of initial retention in any implant type placement had been ruled out very important step as it related with the integration process would be proceed between the dental implant surface and the surrounding bone. Failure in achieving an initial retention will allow the dental implant placed unstable and might promoted an implant placement from failure through the present of gap between bone and implant. The gap will fulfill with fibrous tissue therefore the bone would be failed to integrate with the implant surface and the inflammatory process would be than taken part.

In this paper presented three different types of implant placement according to the period after tooth extraction. 
As shown in case 1, which has short and thin alveolar crest width in the anterior region as well as a narrow alveolar crest in the region of tooth 26 , a short implants dimension and the use of hand bone reamer were helpful as it avoid to vital structures and implant wall perforation.

Observation of 4 months after immediately insertion of two implants into fresh alveolar socket in the region of teeth 15 and 24 resulted with success showed with no implants mobility and presented with healthy surrounding mucosa. Those two implants were found stable the same as given by the other implants which had been inserted in the alveolar crest of 6 months to 1 year after tooth extraction as shown in teeth $11,12,14,16,25,26,34,36$.

As well as in case 2, in the alveolar bed which had been received bone graft with a mixture of autogenous and allograft bones and placed by three dental implants showed with a good result.

All those dental implants had been inserted in those three different alveolar crest situations showed had been integrated with success. In my opinion three primary important consideration should be taken to achieve success in implant placement are: 1) placement of the implants into a good host with no systemic factors problem, 2) the surgical procedure according to the dental implant type should be carefully followed, and 3) the initial fitting of the implant body to the bone must be achieved, lost of that initial fitting may lead a failure as the bone may failed to integrate with the dental implant surfaces.

\section{REFERENCES}

1. Bicon Dental Implants Bulletin. Available at: http://www.bicon. com/news/n_publications.html. Accessed February 27, 2007.

2. Gotfredsen K, Wennerberg A, Johansson C, Skovgaard LT, HjortigHansen E. Anchorage of TiO2-blasted, HA-coated, and machined implants; an experimental study with rabbits. J Biomed Mater Res 1995 October; 29(10):1223-31.
3. Karabuda C, Sandalli P, Yalcens S, Steflik DE, Parr GR. Histologic and histomorphometric comparasion of immediately place hydroxyapatite-coated and titanium plasma-sprayed implants: a pilot study in dogs. Int J Oral Maxillofac Implants 1999 Jul-Aug; 14(4):510-5.

4. Novous AB Jr, Souza SL, de Oliveira PT, Souza AM. Histomorphometric analysis of the bone-implant contact obtained with 4 different implant surface treatments place side by side in the dog mandible. Int J Oral Maxilollifac Implants 2000 May-June; 17(3):377-83.

5. Yong Chan L. The unique quality of bicon implant system clinical application. Dental Success 2004; 24(6):732.

6. She Hi H. Use of Bicon implant, placement without the need of sinus lift (I); Procedure, Clinical Implant,11/12. 2004.

7. She Hi H. Use of Bicon implant, placement without the need of sinus lift (II). Process of Prosthetic Restoration. Clinical Implant, 01/01, 2005.

8. Urdaneta R, Chuang SK, Marincola AW. Two-year retrospective evaluation of a unique restoration for single implants. IADR/AADR/ CADR $80^{\text {th }}$ General Session, Honololu, HI, March 2004. Available at: http://www.bicon.com/news/n publications.html.

9. Woo VV, Chuang SK, Daher S, Muftu A, Dodson TB. Dentoalveolar reconstructive procedures as a risk factor for implant failure. J Oral Max Fac Surg 2004 July; 62(7):773-80. Accessed February 27, 2007.

10. Leary J, Hiryama M. Use of integrated abutment crowns to enhance the aesthetics of maxillary anterior restoration. AO General Session, San Francisco, CA, 2004 (March). Available at: http://www.bicon. com/news/n_publications.html. Accessed February 27, 2007.

11. Yoo RH, Chuang SK, Erakat M, Weed M, Dodson TB. Changes in crestal bone levels in the setting of immediately loaded implants. Int J Oral and Maxillofacial Implants 2005 March-April; 21(2):253.

12. Gentile M, Chuang SK, Dodson T. Survival estimates and risk factors for failure with $6 \times 5.7 \mathrm{~mm}$ implant. Int J Oral and Maxillofacial Implants 2005 November-December; 20(6): 930-37.

13. Abadallah J, Assaf A. Immediate abutment placement for one-stage implant surgery. Arab Dental J 1999; 37:55-61.

14. Coen P. Placement of replace select Ti-unite-coated type implants using combination of immediate and submerge technique after tooth extraction. Dent J (Maj Ked Gigi) 2006 April-June; 39(2):48-53.

15. Coen P. Surgical technique for achieving implant parallelism and measurement of the discrepancy in panoramic radiograph. J. Oral Max Fac Surg 2006 May; 64(5):799-803. 